https://doi.org/10.30910/turkjans.680075

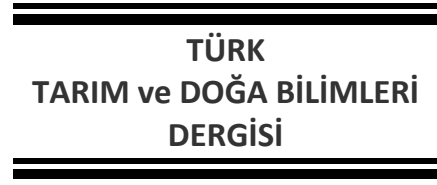

TÜRK

DERGISI

\title{
Araştırma Makalesi \\ Polygonum cognatum Meissn. Ve Funguslu Ortamda Sentezlenen Gümüş Nanopartiküllerinin (AgNP) Antimikrobiyal Özelliklerinin Araştırılması
}

\author{
Nevcihan GÜRSOY ${ }^{1 *}$, Sezai ELAGÖZ², Evren GÖLGE ${ }^{1}$ \\ ${ }^{1}$ Sivas Cumhuriyet Üniversitesi, Mühendislik Fakültesi, Gıda Mühendisliği Bölümü, Sivas \\ ${ }^{2}$ Sivas Cumhuriyet Üniversitesi, Mühendislik Fakültesi, Nanoteknoloji Mühendisliği Bölümü Sivas \\ *Sorumlu yazar: ngursoy@cumhuriyet.edu.tr
}

Geliş Tarihi: 11.12 .2019

Düzeltme Geliş Tarihi: 28.12.2019

Kabul Tarihi: 05.01.2020

\section{Özet}

Bu çalışmada, Madımak (Polygonum cognatum Meissn.) ve A. alternata ve üzerinde sentezlenen gümüş nanopartiküllerinin (AgNP) antimikrobiyal etkileri araştııılmıştır. Antimikrobiyal etkinin araştııılmasında patojen bakteri suşlarından gıdalarda yaygın olarak bulunan ve tüketimleri sonucunda ciddi sağlık sorunlarına neden olan Staphyloccus auerus, Enterecoccus fecalis, ve Escherichia coli bakteri türleri ile Aspergillus niger, Penicillium chrysogenum ve Fusarium oxysporium fungus türleri kullanılmıştır. Sentezlenen AgNP'lerin karakterizasyonunda UV-Vis Spektrofotometri Atomik Güç Mikroskobu (AFM) ve Yüksek Kontrastlı Taramalı Elektron Mikroskobu (CCTEM) kullanılmıştır. Antimikrobiyal etkinliğin belirlenmesi amacıyla uygulanan Kirby Bauer Disk Difüzyon testi verilerinin istatistiki değerlendirmelerinde veriler ortalama \pm standart hata olarak ifade edilmiş ve SPSS Ver. 22 yazılım programı kullanılarak analiz edilmiştir. Madımak ve A. alternata üzerinde sentezlenen AgNP'leri sadece $F$. oxysporum'da antifungal etki göstermemiştir. Bununla birlikte diğer fungus türleri üzerinde yüksek bir antifungal etkiye sahip olduğu ancak bu etkinin antifungal ajan Amphotericin B'ye göre bir üstünlüğünü olmadığı saptanmıştır. Her iki sentez sonucunda elde edilen AgNP'lerin çalışılan tüm bakteri türlerinde antibakteriyel etkiye sahip olduğu belirlenmiştir. Ancak A. alternata üzerinde sentezlenen AgNP'lerinin S. aureus üzerinde hem Madımak üzerinde sentezlenen AgNP'lerden hem de Ampicilin antibakteriyel ajanından daha güçlü bir antibakteriyel etkinliği olduğu tespit edilmiştir $(p<0.05)$.

Anahtar kelimeler: Madımak, A. alternata, gümüş nanopartikül, antimikrobiyal.

\section{Investigation of Antimicrobial Effects of Silver Nanoparticles (AgNPs) Synthesized on Polygonum cognatum Meissn. and Fungus Environment}

\begin{abstract}
In this study, antimicrobial effects of silver nanoparticles (AgNPs) synthesized on Madımak (Polygonum cognatum Meissn.) and $A$. alternata were investigated. The antimicrobial activity was investigated by using bacterial species such as Staphyloccus auerus, Enterecoccus fecalis, Escherichia coli and fungus species such as Aspergillus niger, Penicillium chrysogenum and Fusarium oxysporium, which are common in foods and caused serious health problems as a result of consumption. UV-Vis Spectrophotometry, Atomic Force Microscope (AFM) and High Contrast Scanning Electron Microscope (CCTEM) were used for particle characterization of synthesized AgNPs. In the statistical evaluation of Kirby Bauer Disk Diffusion test results, which were applied to determine the antimicrobial efficacy, the data were expressed as mean \pm standard error and analyzed by using SPSS V22 software. AgNPs synthesized on Madımak and A. alternata showed no antifungal effect on $F$. oxysporum. However, it has been found that it has a high antifungal effect on other fungi species but this effect has no superiority over Amphotericin B agent. It was determined that AgNPs obtained from both syntheses had antibacterial effect on all bacterial species studied. However, it was found that AgNPs synthesized on $A$. alternata had a stronger antibacterial activity on S. aureus than AgNPs synthesized on Madımak and Ampicillin, an antibacterial agent $(p<0.05)$.
\end{abstract}

Key words: Madımak, A. alternata, silver nanoparticle, antimicrobial. 


\section{Giriş}

Son yıllarda mikroorganizmaların çeşitli antibiyotikleri dayanıklılık geliştirmesi ve bu nedenle çok basit hastalıkların tedavi olanaklarının güçleşmesi güncel olarak tartışılan önemli konulardan biri haline gelmiştir. Bu nedenle bilim adamları çeşitli tekniklerle üretilen nano partiküllerin çok düşük oranlarının gösterdiği yüksek etkileri, dokulara yüksek penetrasyon kabiliyetleri ve küçük moleküllerin kanda çok daha kolay taşınımları, hedef doku ya da moleküllere bağlanarak diğer dokulara zarar vermeme özellikleri nedeniyle etkili bir çözüm olacağını bildirmektedirler (Ghassan ve ark., 2013). Nanopartikül üretiminde uzun zamandır kullanılan fiziksel, kimyasal teknolojiler sayesinde yüksek çözünürlü küçük partiküller, kısa sürede üretilebilmesine rağmen toksik içeriklerinin yüksek olması, partikül kararlılıklarının iyi olmaması ve pahalı olması nedeniyle yeni teknolojiler arayışını gerekli kılmıştır. Sonuçta, çevre dostu, toksik madde içeriği az, canlı hücrelerden nanopartikül üretimi esasına dayanan "Yeşil Nanoteknoloji" terimi ortaya çıkmıştır (Narayanan ve Sakthivel, 2010). Yeşil nanoteknoloji kapsamında özellikle yeşil bitki ekstraktları ve mikroorganizmalar kullanılmaktadır. Bu anlamda birçok yeşil bitki ekstraktları nanopartikül üretiminde başarılı bir şekilde kullanılmaktadır (Krishnavaj ve ark., 2010). Madımak Polygonaceae, (Kuzukulağıgiller) familyasında yer alan bir bitkidir. Anadolu'nun Sivas, Tokat gibi bölgelerinde bahar aylarında doğada kendiliğinden yetişen, genç sürgünleri yenilen, çok yıllık otsu bir bitkidir. Yüksek fenolik içeriğe sahip olup, antioksidan ve antimikrobiyal özelliğe sahip olduğu bildirilmektedir (Önen ve ark., 2014). Madımağın antienflamatuar bir etkisinin varlığı ya da biyolojik oksidasyona dirençli olup olmadığı bilinmemektedir. Bununla birlikte, madımağın biyolojik etki mekanizmaları ve farmakolojik özellikleri henüz tamamıyla açıklığa kavuşturulmamıştır. Hem yeşil bitki ekstraktı hem de mikroorganizma kullanılan biyosentezde, canlı hücrelerin metal iyonlarını indirgeyerek toksik metallerin toksitelerini azalttıkları bildirilmiştir (Saifuddin ve ark., 2008). Bakteri, fungus, maya kullanılarak nanopartikül sentezi diğer kimyasal ve fiziksel yöntemlere nazaran daha az toksik olmaları ve çevreye zarar vermemeleri nedeniyle öne çıkmaktadırlar. Bu mikroorganizmalar içerisinde fungusların, biyolojik üretim sırasında çalkalama ve diğer uygulamalara dayanıklı olmaları kolaylıkla üreyebilmeleri nedeniyle bakteri ve mayalara oranla daha başarılı olduğu bildirilmektedir (Narayanan ve Sakthivel, 2010). A. alternata, insan patojeni olarak gelişen ve hastanın bağışıklık sistemini tahrip eden bilinen en iyi Alternaria türüdür. Ayrıca, Alternaria sporları en yaygın hava alerjenlerinden birisidir. $A$. alternata genellikle verimli arazilerde ve birçok farklı toprak türünde üst katmanlarda bulunmaktadır (Domsch ve ark., 2008). Son yıllarda, çeşitli fungus türleri nanopartikül üretiminde kullanılmaya başlanmıştır (Gajbhiye ve ark., 2009; Ingle ve ark., 2009; Sarkar ve ark., 2011). Literatürde bitki ve fungus ortamında sentezlenen gümüş nanopartiküllerinin (AgNP) antimikrobiyal özelliklerinin karşılaştırıldığı bir çalışmaya rastlanmamıştır. Bu nedenle, bu çalışmada, endemik ve gıda olarak tüketimi yaygın olan madımak bitki ekstraktı ve $A$. alternata fungus hücre süspansiyonunda sentezlenen AgNP'inin antimikrobiyal özelliklerinin karşılaştırılarak araştırılması amaçlanmıştır.

\section{Materyal ve Metot Bitki materyali}

Çalışmada kullanılan Madımak ( $P$. cognatum Meissn.) Sivas'ın Hafik ve Zara ilçelerinden MayısHaziran aylarında toplanmıştır. Uygun koşullarda Laboratuvara getirilmiş ve kullanım aşamasında kadar kontrollü koşullarda saklanmıştır.

\section{Mikroorganizma izolatları}

Gümüş nano partiküllerinin (AgNP) sentezlenmesinde kullanılan olan $A$. alternata ve antimikrobiyal özelliklerin araştırılmasında kullanılan $A$. niger, $F$. oxysporium ve P.chrysogenum, fungus izolatları Sivas Cumhuriyet Üniversitesi, Gıda Mühendisliği, Gıda Mikrobiyolojisi ve Nanogıda Teknolojileri laboratuvarından, Gram (+) ve (-) bakterilerden $S$. auerus, E. faecalis ve E. coli izolatları ise S.C.Ü., Tıp Fakültesi, Mikrobiyoloji Laboratuvarından temin edilmiştir.

\section{Madımak ekstresinde AgNP sentezi}

Madımak üzerinde AgNP sentezlenmesinde Matos ve Courrol, 2014'ün bildirdiği yöntem modifiye edilerek uygulanmıştır. Madımak yaprakları distile suda temizlendikten sonra laminar flow içerinde, filtre kağıtlarının üzerinde kuruması tamamlanan yapraklar blender ile $3 \mathrm{dk}$ homojenize edilerek, küçük parçalara ayrılmış daha sonra 24-48 saat süre boyunca $60{ }^{\circ} \mathrm{C}$ 'de etüvde kuruması sağlanmıştır. Kurutulan bitki yaprakları ya hemen kullanılmış ya da analizin yapılacağı tarihe kadar vakumlu ambalajlarda laboratuvar şartlarında muhafaza edilmiştir. Daha önce hazırlanmış ekstraksiyondan alınarak yada taze olarak yaklaşık 10-20 gr madımak 300 ml'lik erlenmayer içerisine alınarak $100 \mathrm{ml}$ distile su eklenmiştir. Karışım kaynadıktan $60{ }^{\circ} \mathrm{C}^{\prime}$ de 5 dakika haşlanmıştır. Haşlama sonrası Watman No.1 filtre kağıdı kullanılarak süzülmüştür. Filtre edilmiş 
karışım 18000 rpm' de 25 dakika santrifüjlenmiştir. Elde edilen filtrat su bazlı $1 \mathrm{mM} \mathrm{AgNO}_{3}$ erlenlere eklenerek oda sıcaklığında 6-24 saat 150 rpm' de orbital karıştırıcıda inkübe edilmiştir. Aynı işlem kontrol grup içinde uygulanmıştır.

\section{A. alternata üzerinde AgNP sentezi}

A. alternata hücre filtratında AgNP sentezi Gajbhiye ve ark.,(2009)'nın kullandığı metod modifiye edilerek kullanılmıştır. AgNP'nin funguslu ortamda sentezlenmesinde $A$. alternata Potato Dextrose Agar (PDA) besi ortamında $25^{\circ} C^{\prime}$ de 3-4 gün inkübe edilerek geliştirilmiştir. Saf olarak gelişimi sağlanmış kültürlerden $250 \quad \mathrm{ml}$ 'lik erlenmayer içerisinde Potato Dextrose Broth Agar (PDB) sıvı besi ortamına 6-10 disk eklenmiştir. PDB ortamında gelişimleri sağlanan $A$. alternata 25 ${ }^{\circ} C^{\prime}$ da 250 rpm'lik çalkalayıcıda 48 saat inkübe edilmiştir. İnkübasyondan sonra fungus miselleri Watman No.1 ile filtre edilerek, steril distile su ile tekrar sulandırılmış ve 24 saat $25^{\circ} \mathrm{C}^{\prime}$ de inkübe edilmiştir. Elde edilen süspansiyon Watman No. 42 ile filtre edilmiştir. Elde edilen hücre filtratı $1 \mathrm{mM}$ $\mathrm{AgNO}_{3}$ eklenerek oda sıcaklığında 24-48 saat 180 rpm'de inkübe edilmiştir.

\section{Sentezlenen AgNP'nin karakterizasyonu UV-Vis spektrofotometri}

Madımak ekstresi ve fungal özüt kullanılarak sentezi yapılan AgNP'lerin yüzey plazmon rezonansı (SPR) ile absorbans spektrum ölçümleri UV-Vis Spektrofotometrede ölçülmüştür. Çalışmada, $1 \mathrm{~nm}$ çözünürlüğe sahip UV-Vis absorpsiyon spektrofotometresi 250-500 nm'de kullanılmıştır.

\section{Atomik güç mikroskop (AFM) analizleri Sentezlenmiş AgNP'nin 3 boyutlu görüntüleri Atomik Force Microscopy (AFM) kullanılarak elde edilmiştir. Sentezlenen AgNP'leri silikon film üzerine kaplanarak boyut özellikleri ve yüzey topografyası belirlenmiştir.}

\section{Transmisyon elektron mikroskop (CCTEM) analizleri}

Sentezlenen AgNP'nin partikül boyut ve şekil özelliklerinin mikroskobik değerlendirilmesinde Yüksek Kontrastlı Transmisyon Elektron Mikroskobu (CCTEM) kullanılmıştır. Sulu süspanyonlarda hazırlanacak AgNP'ler 400 mesh karbon film kaplı bakır gridler üzerine bırakıldıktan sonra sulu kısım evaporatör yardımı ile uzaklaştırılarak, 120 kV'de çalışılmıştır.

\section{Antimikrobiyal özellik tespiti Kirby Bauer agar disk diffüzyon testi}

Madımak ve $A$. alternata üzerinde sentezlenmiş AgNP'lerinin in vitro antimikrobiyal etkisinin araştırılmasında patojen bakteri türleri $E$. coli, E. faecalis, $S$. auerus ile A.niger, P.chrysogenum ve $F$. oxysporium fungus türleri kullanılmıştır. Bakteri kültürleri Mueller Hinton Agar (MHA) ve Nutrient Agar; fungus türleri ise PDA ortamlarına yayma yöntemi ile ekilmiştir. Ekim sonrası bakteri kültürleri $37 \pm 0.1{ }^{\circ} \mathrm{C}$ de, fungus türleri ise $25^{\circ} \mathrm{C}^{\prime}$ de $18-24$ saat inkübe edilmiştir. Pozitif kontrol olarak ticari olarak temin edilmiş standart antibakteriyel Ampicilin ve antifungal AmpB diskleri kullanılmıştır. $\mathrm{AgNO}_{3}$ eklenmemiş fungal hücre süspansiyonu gerektiğinde negatif kontrol olarak steril boş diske emdirildikten sonra yada sadece steril boş diskler kullanılmıştır. İnkübasyon sonrasında oluşan inhibisyon zonlarının ölçümleri $(\mathrm{cm})$ yapılmıştır.

\section{Istatiksel analiz}

Çalışmada elde verilerinin istatistiki değerlendirmelerinde veriler ortalama \pm standart hata olarak ifade edilmiş ve SPSS Ver. 22 yazılımı kullanılarak analiz edilmiştir. Veriler parametrik test varsayımlarını karşılamadığı durumlarda gruplar birbirleri ile karşılaştırılırken Mann-Whitney $U$ ve Ki-Kare testi uygulanmıştır. $P$ değerinin 0.05 'ten küçük olduğu durumlarda fark istatistiksel olarak anlamlı kabul edilmiştir.

\section{Bulgular ve Tartışma \\ Madımak ve A. alternata üzerinde AgNP sentezi \\ PDB ortamında geliştirilen $A$. alternata} hücre filtratına $50 \mathrm{ml} 1 \mathrm{mM} \mathrm{AgNO}{ }_{3}$ eklenmiş ve $180 \mathrm{rpm}$ 'de $25^{\circ} \mathrm{C}^{\prime}$ da $24-48$ saat inkübe edildikten sonra bulanık beyaz-açık sarıdan kahverengine dönüşen renk değişimi gözlenerek nanopartikül üretimi gerçekleştirilmiştir (Şekil 1). Yapılan araştırmalarda daha önce madımak bitkisi üzerinde AgNP sentezlendiğine dair bilgiye rastlanılmadığından benzer çalışmalar örnek gösterilememiştir. Bununla birlikte çeşitli bitkisi ekstreleri üzerinde AgNP sentezinin gerçekleştirildiği $\mathrm{AgNO}_{3} \quad$ eklendikten sonra gözlenen sarı-kahverengi renk oluşumları ile tespit edildiği bildirilmiştir (Florence ve ark., 2013; Matos ve Currol, 2014). 


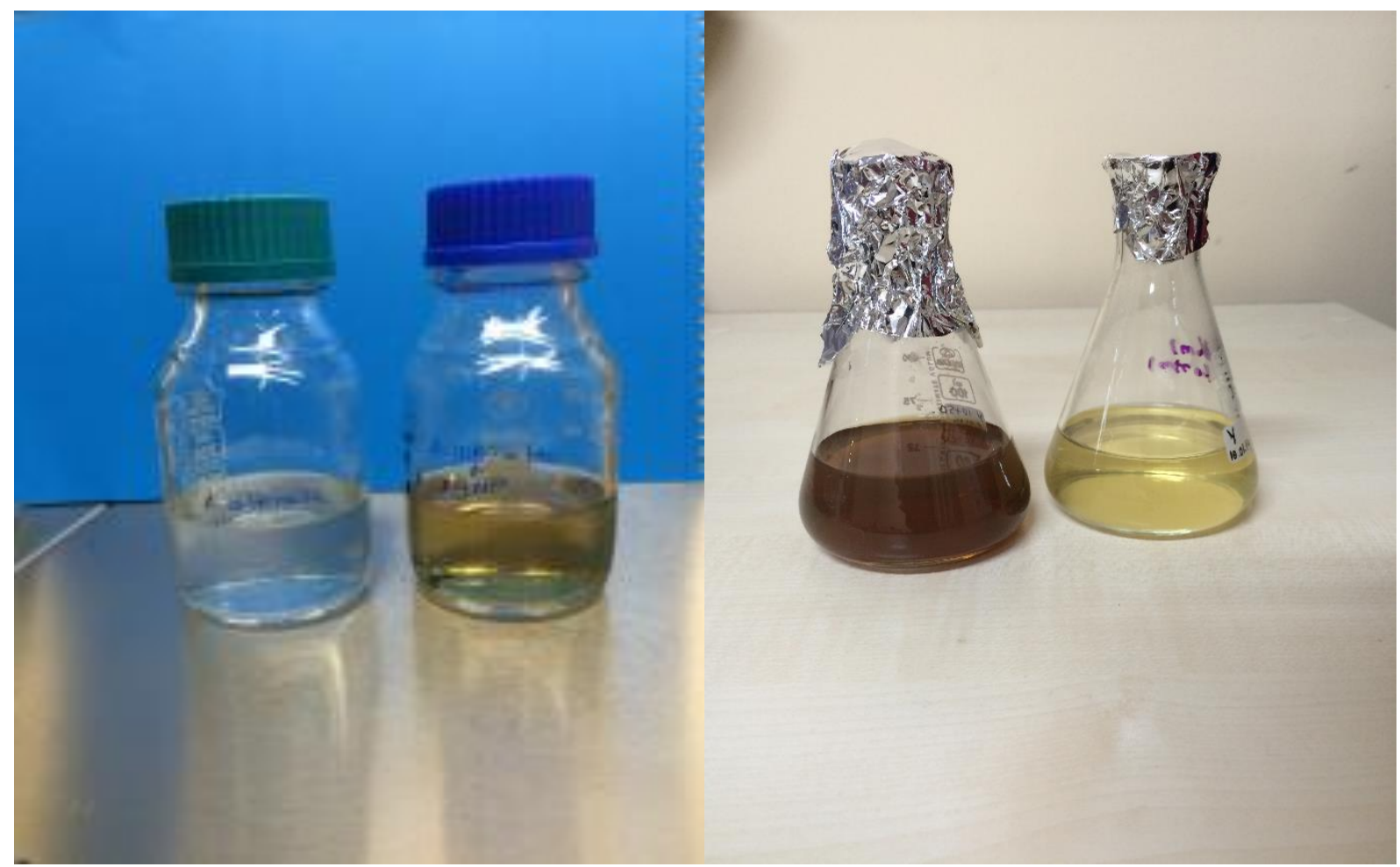

Şekil 1. Madımak ve A.alternata fungal filtratlarında AgNP üretimini gösteren renk değişimi.

Bitki ekstraktlarının metal iyonlarını indirgeme özellikleri 1900'lü yıllardan beri bilinmekle birlikte indirgeme ajanlarının doğal mekanizmaları tam olarak anlaşılamamıştır. Son 30 yıldır kabul gören uygulama ise yeşil bitki aksamının tamamı yada bitki dokusunun metal tuzlarını indirgeme özelliğine dayandırımaktadır (Pande ve ark., 2015; Kandasamy ve ark., 2017). AgNP oluşum reaksiyonu, fungus hücresine $\mathrm{AgNO}_{3}$ eklenmesi ile metal iyonunun $\mathrm{Ag}^{+\prime}$ nın $\mathrm{Ag}^{0}$ ' a indirgenmesiyle ile gerçekleşmektedir. Fungal hücrelerin hücre duvarında metallerle bağlanabilme yeteneği olan enzimlerini hücre dışına salgılayabilmesi sebebiyle ekstraselüler üretime olanak sağlanması AgNP üretiminde başarılı olarak kullanılabilmelerine olanak sağlamaktadır. Ayrıca, üretme yeteneğinde olduğu çeşitli enzimlerin $\alpha-\mathrm{NADPH}$ - bağlı indigeme, nitratbağı indirgeme gibi özellikleri nedeniyle nano üretimi hızlandırdığı saptanmıştır. Ayrıca fungus metabolitlerinden biri olan Antrakinon'un metal iyonlarının indirgenmesinde önemli olduğu da çeşitli çalışmalarda bildirilmiştir (Abd El-Aziz ve ark., 2013; Abdel-Hadi ve ark., 2014). Nanopartikül üretiminde başlıca kimyasal ve fiziksel yöntemler kullanılmaktadır. Bununla birlikte biyolojik sentez yöntemlerinin diğer yöntemler gibi yan etkilerinin olamaması, daha ekonomik, hızlı, kolay uygulanabilir ve çevre dostu güvenilir bir yöntem olması dolayısıyla tercih edilmektedir (Florence ve ark., 2013).

\section{Sentezi yapılan AgNP'nin karakterizasyonu UV-Vis analizi}

Nanopartiküllerin varlığının ispatlanmasında metalde var olan lokalize yüzey plazmon rezonansını uyarılması, bir elektrik alan oluşturarak belirli bir dalga boyunda rezonans oluşturması ve o dalga boyunda oluşan güçlü ışık saçılımın değerlendirilmesi amacı ile UV-Vis Spektrofotometre kullanılmıştır. Spektrofotometrik analizlerde $\mathrm{Ag}^{0}$ iyonlarının varlığının kanıtı olan partikül yüzey plazmon rezonansı (SPR) ölçülmektedir. AgNP'nin SPR etkinliği partiküllerin boyut, şekil ve dielektrik özelliğine bağlı olarak farklı seviyelerde gözlenmektedir (Ingle ve ark., 2008). Çalışmada kullanılan Madımak ve $A$. alternata üzerinde sentezlenen AgNP'lerin UV-Vis Spektrofotometrik ölçümleri 250-500 nm ölçüm aralığında maksimum absorbans değerleri sırasıyla 425 ve $420 \mathrm{~nm}$ 'de alınmıştır (Şekil 2). Yapılan literatür çalışmalarında Madımak üzerinde AgNP sentezi konusunda çalışmaya rastlanmamıştır. Bununla birlikte çalışma verilerine paralel olarak $M$. balbisiana, $A$. indica ve $O$. tenuiflorum hindistan bitki yaprak ekstreleri üzerinde sentezlenen AgNP'i $15,30,45$ dakika ve 24 saat UV-Vis analizleri 200$700 \mathrm{~nm}$ absorbans aralıklarında çalışılmış ve 425$475 \mathrm{~nm}$ absorbans değerleri elde edilmiştir (Lalitha ve ark., 2013; Banerjee ve ark., 2014). A. alternata üzerinde sentezlenen proteinle kaplanmış AgNP'nin genotoksik etkilerinin araştırıldığı bir çalışmada UV-Vis analizleri $250-850 \mathrm{~nm}$ absorbans aralığında yapılmış ve $420 \mathrm{~nm}$ absorbans piki elde 
edildiği, bu durumun AgNP'inin boylamsal plazmonun uyarılmasından kaynaklanabileceğini bildirmiştir (Gajbhiye ve ark., 2009). Yapılan bir çalışmada, $A$. alternata üzerinde sentezlenen AgNP'lerinin UV-Vis analizleri yapılmış ve 425 $\mathrm{nm}$ 'de en yüksek absorbans alındığı bildirilmiştir (Kareem ve ark., 2019). Bir diğer çalışmada ise $A$. flavus kullanılarak AgNP biyosentezi yapılmış ve farklı sürelerde sentezlenen AgNP'lerin UV-Vis analizlerinde $420 \mathrm{~nm}$ aralıklarında maksimum absorbansta belirlenmiştir (Bhangale ve ark., 2018). Fungal biyosentezi yapılmış $1 \mathrm{mM} \mathrm{AgNO}_{3}$ solüsyonu kullanılarak üretilen $\mathrm{AgNP}^{\prime}$ in sferik yapıda oldukları TEM analizleri ile belirlenmiş ve UV-Vis analizi sonucunda nanopartiküllerinin 418

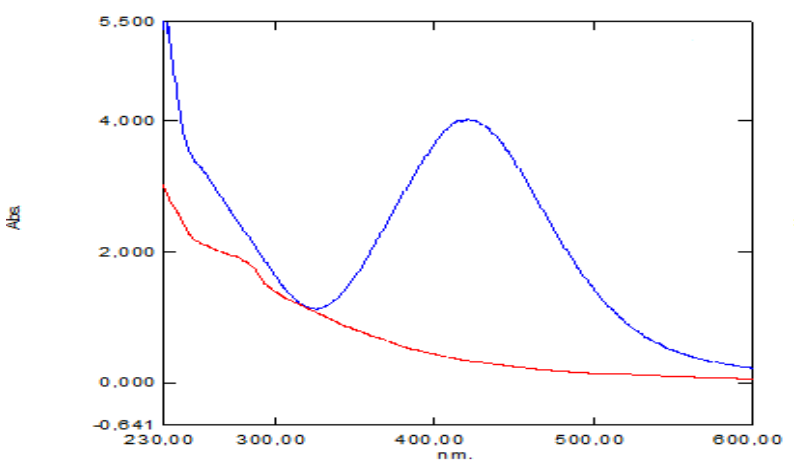

$\mathrm{nm}$ absorbansı belirlenmiştir (Phanjom ve Ahmed, 2017).

\section{AgNP'nin AFM analizleri}

A.alternata ve Madımak üzerinde sentezlenen AgNPlerin boyut, şekil ve varsa kümeleşme görüntüleri Atomik Güç Mikroskobu (AFM) kullanılarak gerçekleştirilmiştir. AFM ile elde edilen görüntülerden nanopartiküllerin boyut, partikül ağırlığı ve hacim değerleri belirlenebilmektedir. Sentezi yapılan Madımak+AgNP'lerinin boyut ve yüzey özellikleri AFM analizi sonucunda incelenen bölgelerde 18.347-235.600 nm, A.alternata+AgNP ise 3.709-227.776 $\mathrm{nm}$ boyutlarında küresel partikül oluşumları ve partiküllerde kümeleşme olduğu belirlenmiştir

(Şekil

3).

要

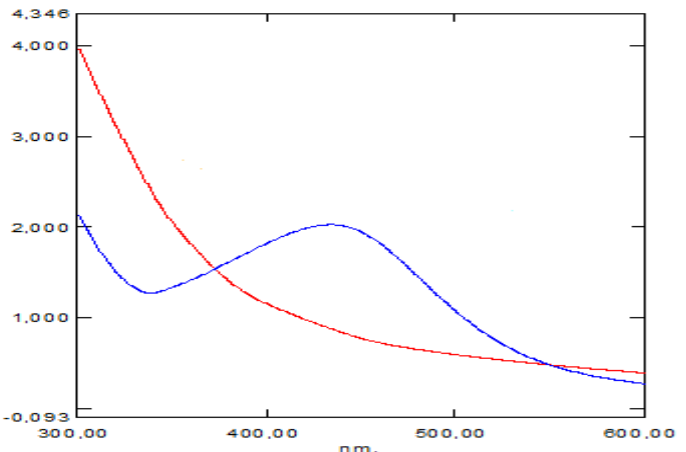

Şekil 2. Madımak ve A. alternata+AgNP'nin UV-Vis ölçüm değerleri.
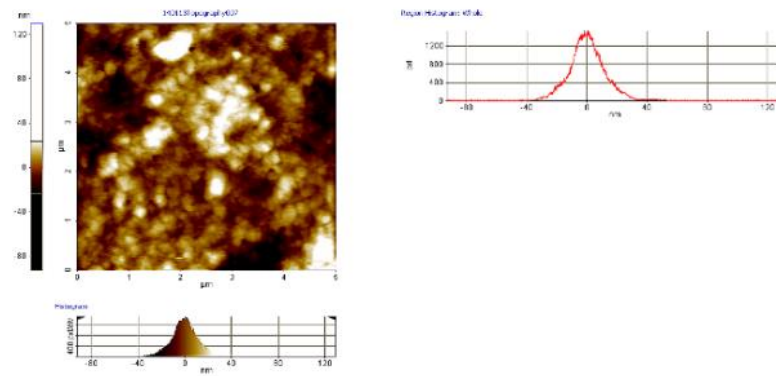

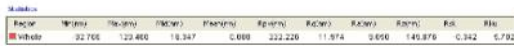

Şekil 3. Madımak ve A. alternata+AgNP'lerin AFM verileri.

\section{AgNP'nin CCTEM analizi}

Madımak ve $A$. alternata üzerinde sentezi yapılan AgNP'lerin CCTEM analiz sonucunda incelenen bölgelerde sırasıyla 45.23-653.2 nm boyutlarında küresel AgNP oluşumları belirlenmiştir (Şekil 4). Bitkisel ekstratlar üzerinde AgNP sentezi yapılan çok sayıda çalışmada, TEM analizleri sonucunda değişen boyutlarda sferik yapılı nanopartikül oluşumlarının varlığı rapor edilmiştir (Gajbhiye ve ark., 2009; Sarkar ve ark., 2011; Matos ve Courrol, 2014).

Sentezlenen AgNP'nin antimikrobiyal etkilerinin değerlendirilmesi

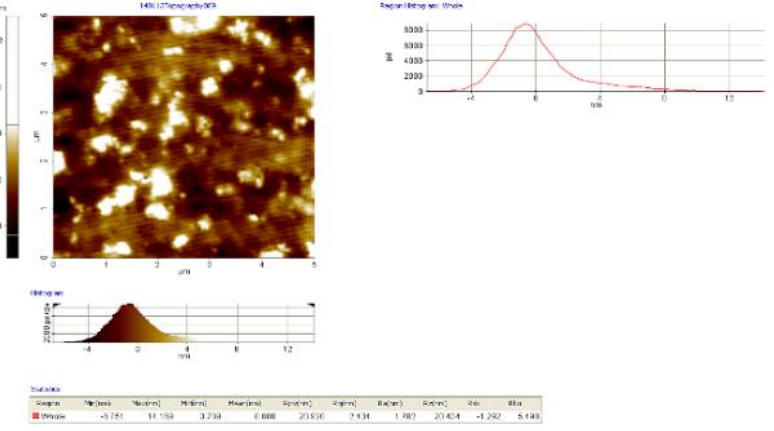

Madımak ve $A$. alternata üzerinde sentezlenen AgNP'lerin antifungal etkinliğinin tespit edilebilmesi amacıyla $A$. niger, F. oxysporum ve $P$. chrysogenum üzerinde test edilmiştir. Pozitif kontrol olarak Amphotericin B antifungal ajanı kullanılmıştır. Sentezlenen AgNP'lerin F. oxysporum türü üzerinde herhangi bir inhibisyon zonu oluşmamıştır bu nedenle değerlendirmelerde kullanılmamıştır. Sentezi yapılan AgNP'lerin antifungal etkinliği fungus türüne göre değerlendirildiği zaman ne $A$. niger ne de $P$. chrysogenum fungus türleri arasında bir fark bulunamamıştır (Şekil 5). Madımak ve A. alternata üzerinde sentezlenen AgNP'lerin antifungal 
etkinliği Amphotericin B kadar yüksek bir antifungal etkinlik meydana getirdiği ancak bu etkinin Amphotericin $B^{\prime}$ e göre bir üstünlüğünü olmadığı saptanmıştır (Şekil 6). Çalışılan fungus türlerinden sadece $F$. oxysporum üzerinde zon gelişimi gözlenmemiştir. Yeşil sentezi yapılan AgNP'in antimikrobiyal etkinliğinin Fusarium türleri arasında en zayıf antifungal etki $F$. oxysporum'da geliştiği rapor edilmiştir (Madrakian ve ark., 2015).
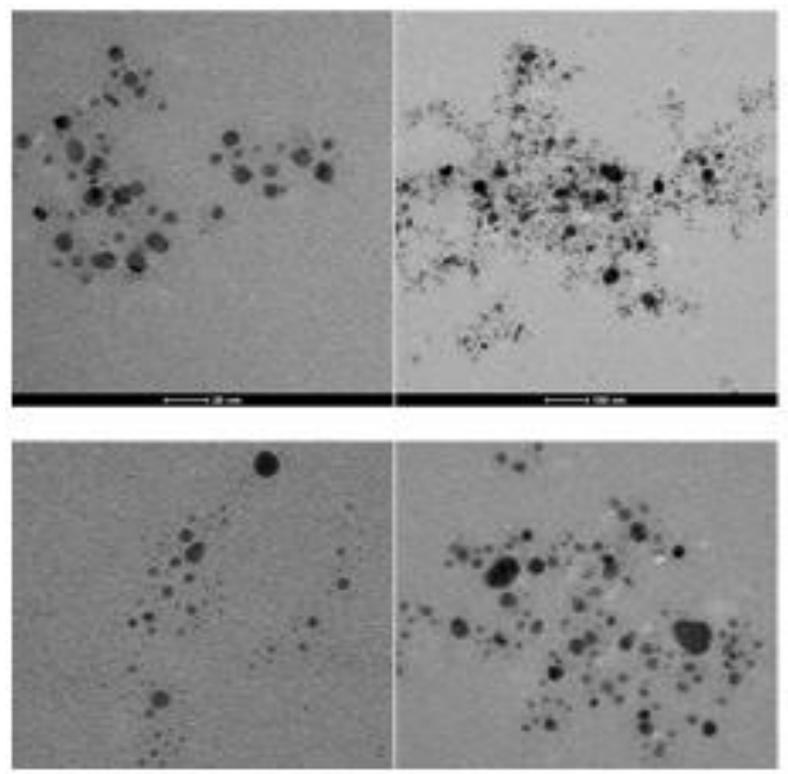

(A)
Gajbhiye ve ark.,(2009), A. alternata üzerinde sentezledikleri AgNP'nin patojenik funguslar Phoma glomerata, P. herbarum, F. semitectum, Trichoderma sp., ve Candida albicans üzerindeki antifungal etkinliğini araştırmışlardır. Sonuçta, en iyi antifungal etki sırasıyla C. albicans, Phoma glomerata ve Trichoderma sp.'de görülürken $P$. Herbarum ve $F$. semitectum üzerinde kayda değer bir etki bulamadıklarını rapor etmişlerdir.
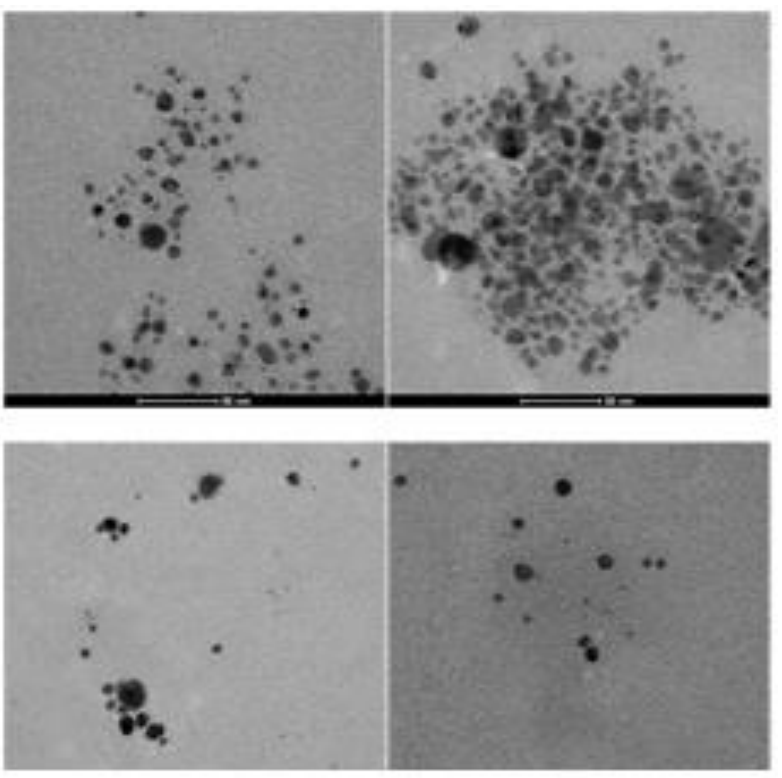

(B)

Şekil 4. Madımak (A) ve A. alternata+AgNP'lerin (B) CCTEM sonuçları.

Yüksek konsantrasyonlarda kullanılan gümüş canlılar için toksik özelliğe sahipken düşük konsantrasyonlarda kullanılan gümüşün toksik olmadığı saptanmıştır. Ayrıca çalışmalarında farklı nano büyüklüğüne sahip partiküllerin $E$. coli üzerindeki antimikrobiyal etkilerini araştırmışlardır. Sonuçta nanopartikül büyüklüğü azaldıkça E.coli üzerindeki antibakteriyal etkinliğin arttığını bildirmişlerdir (Pal ve ark., 2007). Gümüş nanopartiküllerinin anitimikrobiyal ve antifungal etkilerinin araştırmak üzere yapılan bir çalışmada; $A g N P$ ve $A m p B$ kombinasyonunun $A$. flavus ve Candida albicans türlerine karşı antifungal etkinliği arttırdığı bildirilmiştir (Kandile ve ark., 2010). AgNP'nin antifungal etkilerinin araştırıldığı bir çalışmada; antifungal ajanlarla (Amphotericin B, Fluconazole) kombine AgNP'nin 35 ppm'e kadar Aspergillus, Penicillium ve Trichoderma cinsleri üzerinde antifungal etki gösterdiği belirlenmiştir (Kim ve ark., 2009). Çalışmada, Madımak ve $A$. alternata üzerinde sentezlenen AgNP'lerin antibakteriyel etkinliği $E$. coli, E. faecelis ve $S$. aureus bakterileri üzerinde test edilmiştir. Pozitif kontrol olarak Ampicilin antibakteriyel ajan kullanılmıştır. Bu etkinlik bakteri türüne göre değerlendirildiğinde Ampisilin uygulanan bakterilerde; $E$. coli ile $E$. faecelis arasında, $A$. alternata üzerinde sentezlenen AgNP uygulanan bakterilerde ise E. faecelis ile $S$. aureus arasında istatistiksel olarak anlamlı bir fark bulunmuştur $(p<0.05) \quad$ (Şekil 7). A. alternata üzerinde sentezlenen AgNP'lerinin antibakteriyel etkinliği $S$. aureus üzerinde Madımak üzerinde sentezlenen AgNP'lerden hem de Ampicilin antibakteriyel ajanından istatistiksel olarak daha güçlü bir antibakteriyel etkinliği olduğu tespit edilmiştir $(p<0.05)$. Diğer bakterilerde uygulanan A.alternata+AgNP ve Madımak+AgNP'lerinin antibakteriyel etkinliğinin Ampisiline karşı herhangi bir üstünlüklerinin olmadığı görülmüştür (Şekil 8). AgNP ile antibiyotik kombinasyonlarının (Penicilin G, Amoxicilin, Erythromisin, Clindamycin ve Vancomycin) S.aureus ve $E$. coli üzerinde antibakteriyal etkinliklerini araştırıldığı bir çalışmada, AgNP'lerin antibiyotiklerin hepsinin etkinliğini değişik oranlarda arttırdığı ve en yüksek antibakteriyal etkinin $S$. aures'a karşı AgNP+Erythromisin kombinasyonu ile sağlandığını tespit edilmiştir. Ayrıca AgNP'lerin gram negatif bakterilere gram pozitiflerden daha fazla antibakteriyal etkiye sahip oldukları saptanmıştır (Shahverdi ve ark., 2007). Antimikrobiyal 
maddelerin nanopartiküllerle kolayca şelat oluşturma yeteneğine sahip birçok aktif grup, hidroksil ve amid grubu içermesi nedeniyle AgNP ve antifungal madde arasında sinerjist etkinin, antimikrobiyal özelliği artırdığı bildirilmiştir (Mukherjee ve ark., 2008). AgNP ve AgNP+Antifungal ajan Flucanazole, Griseofulvin kombinasyonlarının Trichophyton rubrum

antifungal

etkisini Çalışma sonucunda, AgNP+Antifungal ajan kombinasyonunun AgNP'ye nazaran çok daha etkili olduklarını ve AgNP'nin antifungal ajanın etkinliğini \%50'nin üzerinde arttırdığını bildirmişlerdir (Noorbakhsh, 2011).

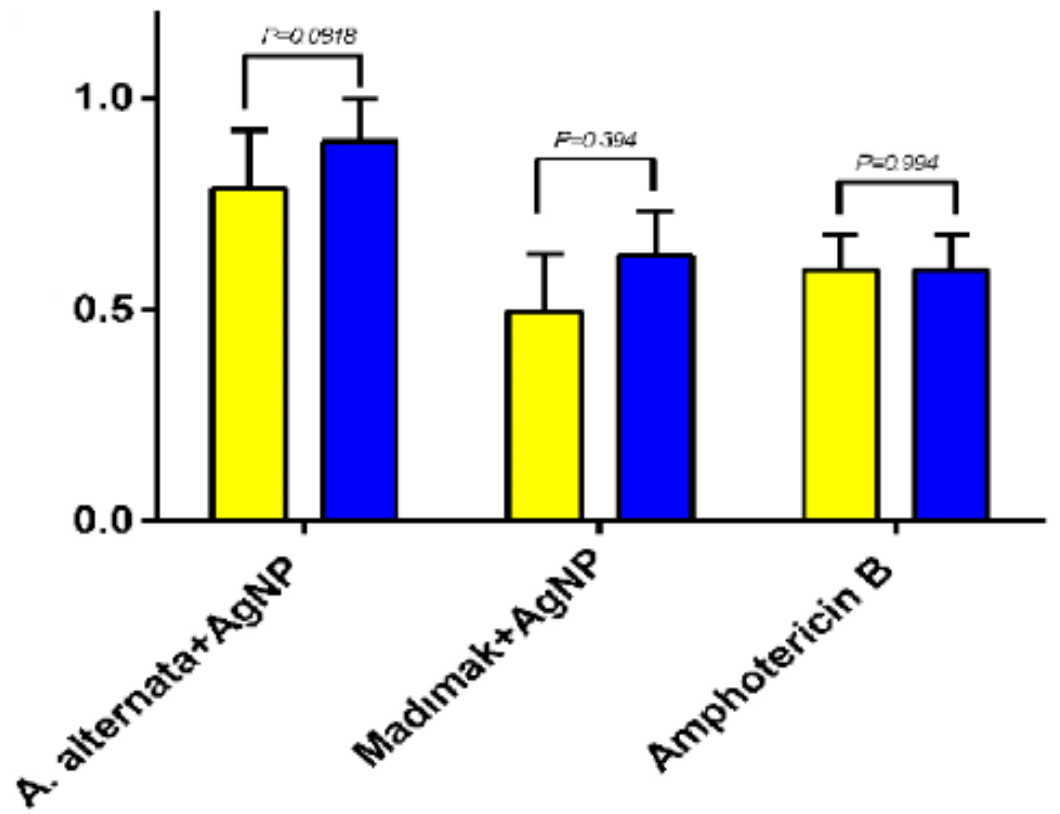

Şekil 5. Madımak ve A. alternata+AgNP'lerinin antifungal etkinliğinin karşılaştırması
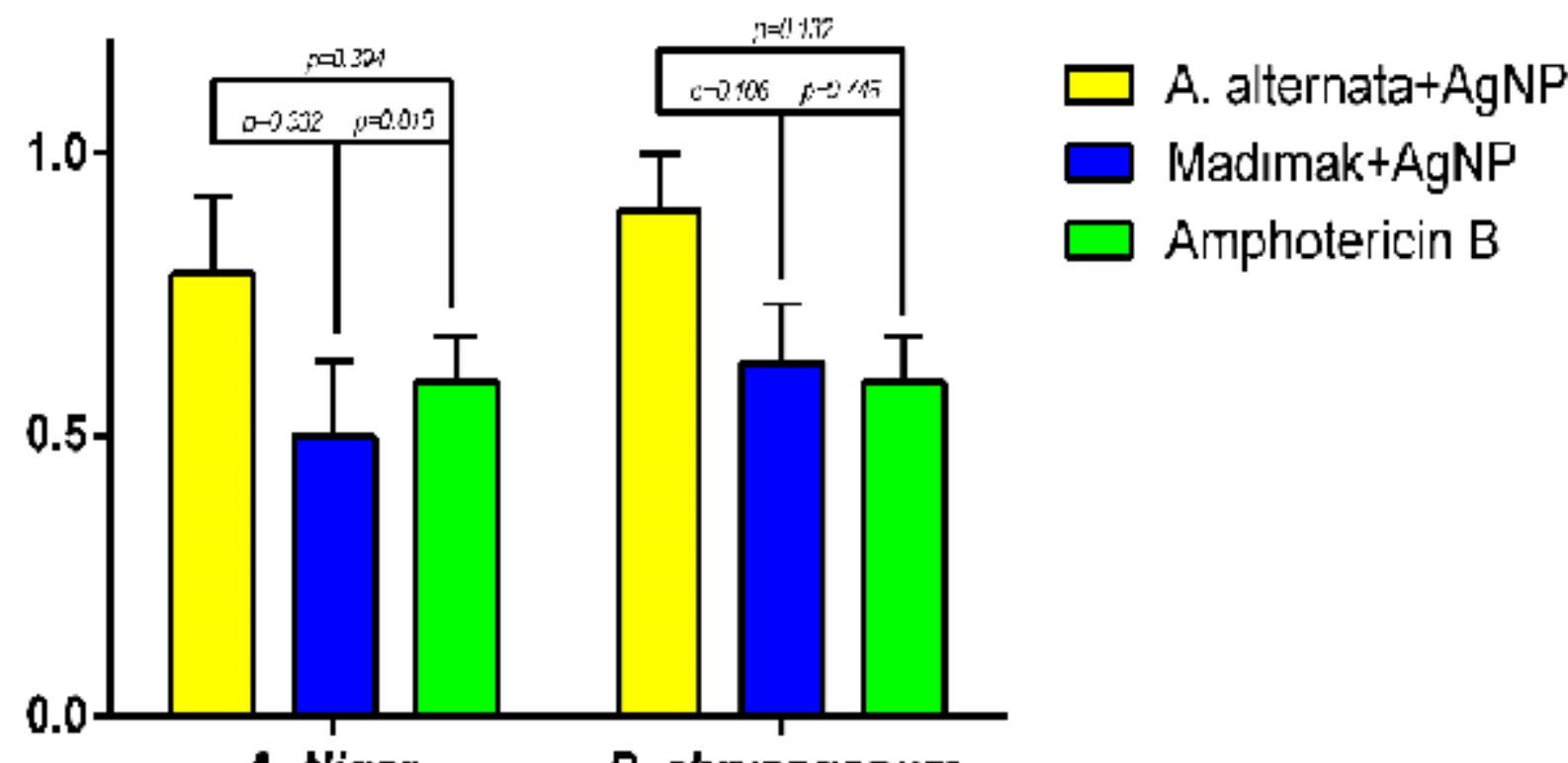

A. Niger

P. chrysogenum

Şekil 6. Madımak ve A. alternata+AgNP'lerin antifungal etkinliğinin karşılaştırması. 


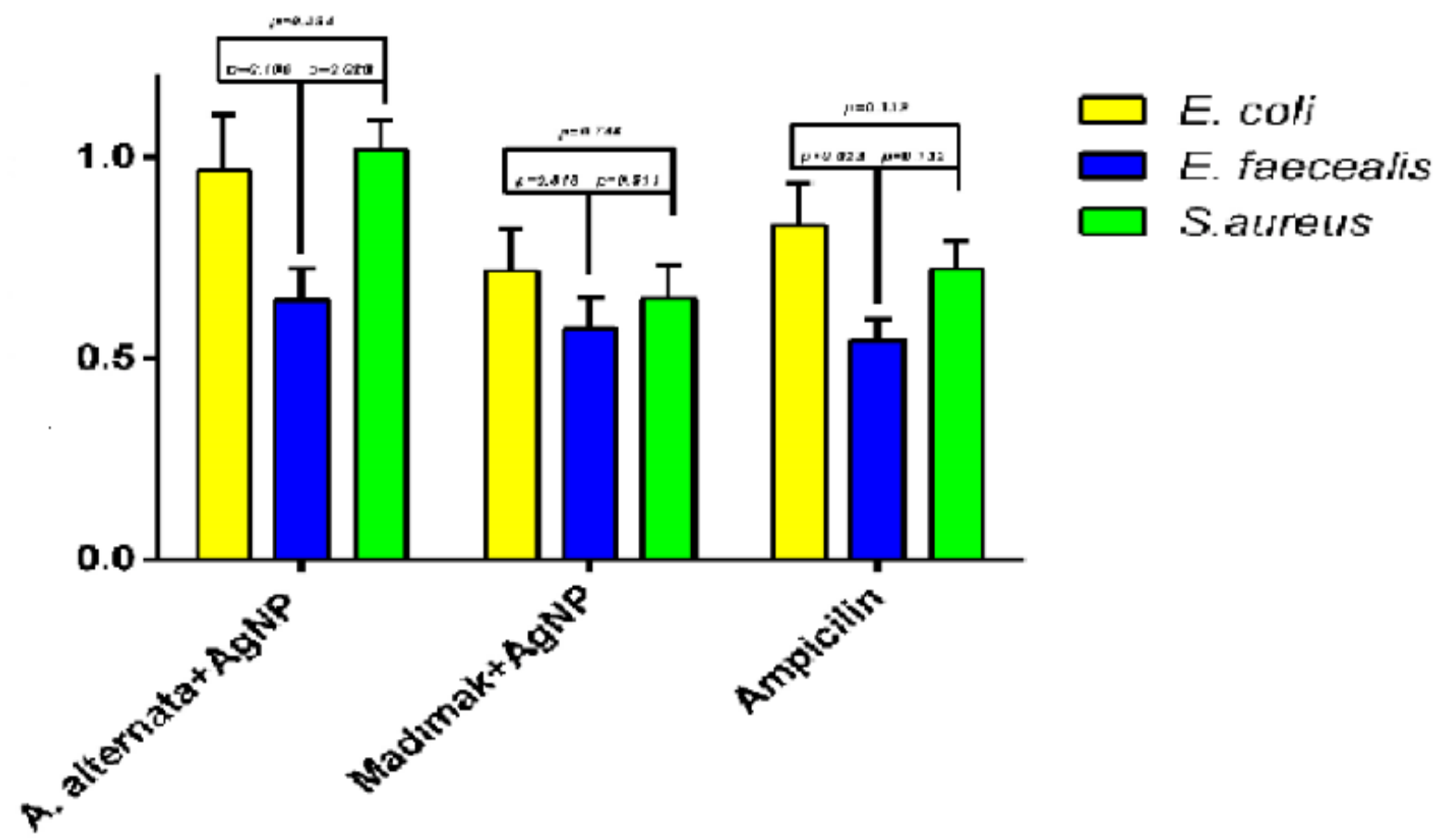

Şekil 7. Madımak ve A. alternata+AgNP'lerin antibakteriyel etkinliğinin karşılaştırması.

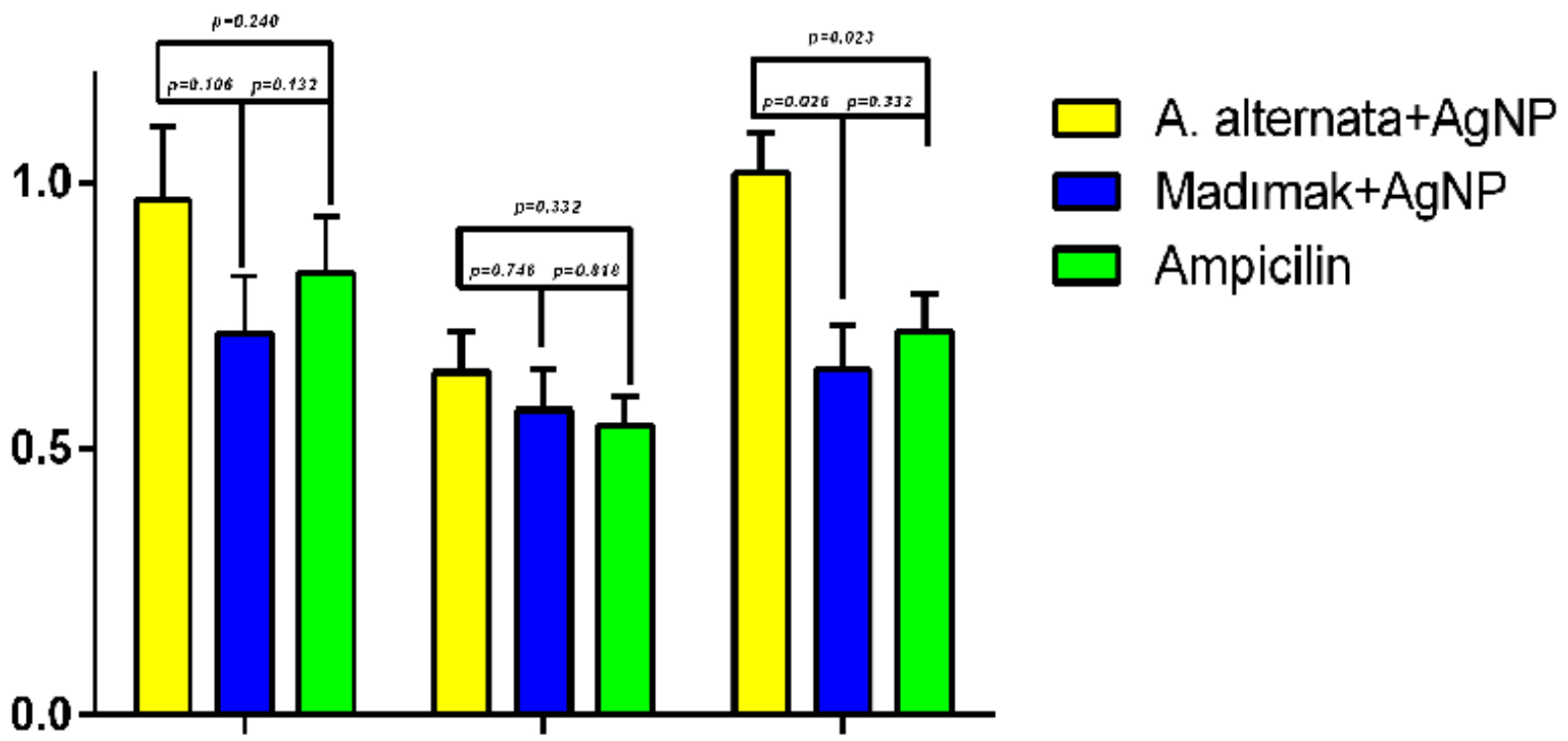

E. coli E. faecealis S. aureus

Şekil 8. Madımak ve A. alternata+AgNP'lerin antibakteriyel etkinliğinin karşılaştırması.

\section{Sonuç ve Öneriler}

Sonuç olarak, Madımak ve A. Alternata üzerinde sentezi yapılan AgNP'nin antifungal ve bakteriyel etkinliğe sahip olduğu belirlenmiştir. Sentezlenen AgNP'in AFM ve CCTEM analizleri sonucunda Madımak ekstresi üzerinde yapılan sentezde kısmen daha büyük nanopartikül üretimi olduğu belirlenmiştir. Nanopartikül büyüklüğü azaldıkça antifungal ve antibakteriyel etkinlik artmaktadır. Bu sonuç daha az miktarda gümüş kullanılarak daha yüksek bir etkinlik elde edilebilmesinin yolunu açması bakımından kıymetlidir. Ayrıca AgNP'lerin hem funguslar üzerinde hem de bakteriler üzerinde güçlü antifungal ve antibakteriyel etkinliklerinin olduğu gösterilmiştir. Bu oldukça geniş spektrumlu etki özelliği AgNP'leri daha dar spektrumlu ilaçlar karşısında bir adım öne çıkarmaktadır. Aynı zamanda tekli yada çoklu antibiyotik direncine sahip bakterilerde dayanıklılık mekanizmasını engelleyerek farklı yeni bir yaklaşım olanağı sağlayabilecektir.

Ayrıca Madımak üzerinde AgNP sentezi konusunda çalışma bulunmaması konu ile ilgili 
gelecekteki çalışmalara örnek olabilmesi farklı bir yaklaşımla antimikrobiyal etkinliğin sağlanması ve uygulanması açısından çalışma verileri diğer araştırmacılara örnek olacak niteliktedir.

\section{Kaynaklar}

Abd El-Aziz, A.R., Al-Othman, M.R., Eifan, S.A., Mahmoud, M.A, Majrashi, M. 2013. . Green synthesis of silver nanoparticles using Aspergillus terreus (KC462061). Dig. J. Nanomater. Biostruct., 8:1215-1225.

Abdel-Hadi, A.M., Awad, M.F., Abo-Dahab, N.F., ElKady, M.F. 2014. Extracellular synthesis of silver nanoparticles by Aspergillus terreus: biosynthesis, characterization and biological activity. Biosci. Biotechnol. Res. Asia, 11: 1179-1186.

Banerjee, P., Satapathy, M., Mukhopahayay, A., Das, P. 2014. Leaf extract mediated green synthesis of silver nanoparticles from widely available Indian plants: synthesis, characterization, antimicrobial property and toxicity analysis. Bioresour. Bioprocess. 1 (3):143-48.

Bhangale, H., Sarode, K.M., Patil, A.M., Patil, D.R. 2018. Microbial synthesis of silver nanoparticles using Aspergillus flavus and their characterization. Springer International Publishing AG, 780 sy.

Domsch, K.H., Gams, W., Anderson, T. 2008. Compendium of Soil Fungi (Vol.2). Academic Press, London.

Florence, O., Tatiana, K., Vernessa, E., Michael, C. 2013. Green Synthesis of Silver Nanoparticles, Their Characterization, Application and Antibacterial Activity. Int. J. Envir. Res. Public Health. 10: 5221-5238.

Gajbhiye, M., Kesharwani, J., Ingle, A., Gade, A., Rai, M. 2009. Fungus-mediated synthesis of silver nanoparticles and their activity against pathogenic fungi in combination with fluconazole. Nanomedicine: Nanotechn., Biology and Medicine. 5(4): 382-386.

Ghassan, M.S., Wasnaa, H.M., Thorria, R.M., Ahmet Abdul, A.A., Abdul Amir, H.K., Abu Bakar, M. 2013. Green synthesis, antimicrobial and cytotoxic effects of silver nanoparticles using Eucalyptus chapmaniana leaves extract. Asian Pac J Trop Biomed. 3(1): 58-63.

Ingle, A., Gade, A., Pierrat, S., Sonnichsen, C., Rai, M.K. 2008. Mycosynthesis of silver nanoparticles using the fungus Fusarium acuminatum and its activity against some human pathogenic bacteria. Curr Nanosci. 4:141-144.
Kandasamy, S., Chinnappan, S., Muthusamy, G., Periasamy, T., Arumugam, S., Balakrishnan, S., Thangasamy, S. 2017. Eco-friendly biosynthesis and characterization of silver nanoparticles using Tinospora cordifolia (Thunb.) Miers and evaluate its antibacterial, antioxidant potential. Journal of Radiation Research and Applied Sciences. 10 (1): 6-12.

Kandile, N.G., Howida, T.Z., Mansoura, I.M., Hemat, M.M. 2010. Silver Nanoparticles Effect on Antimicrobial and Antifungal Activity of New Heterocycles. 3530 Bull. Korean Chem. Soc. 31(12): 120-126.

Kareem, O.S., Oluwagbemiga, T., Adejare, F., Oloyede, R., Enock, O. 2019. Dare Microbial Synthesis of Silver Nanoparticles Using Alternaria alternata and Their Characterization. App. Envi. Res. 41(1): 1-7.

Kim, J., Soonjo, K., Erik, O. 2009. Antimicrobial effect of silver-impregnated cellulose: potential for antimicrobial therapy. Journal of Biological Engineering. 3: 20-27.

Krishnaraj, C., Jagan, E.G., Rajasekar, S., Selvakumar, P., Kalaichelvan, P.T., Mohan, N. 2010. Synthesis of silver nanoparticles using Acalypha indica leaf extracts and its antibacterial activity against water borne pathogens. Colloids Surf B Biointerfaces. 76(1): 50-56.

Lalitha, A., Subbaiya, R., Ponmurugan, P. 2013. Green synthesis of silver nanoparticles from leaf extract Azhadirachta indica and to study its anti-bacterial and antioxidant property. Int. J. Curr. Microbiol. App. Sci. 2: 228-235.

Madrakian, T., Alizadeh, S., Karamian, R., Asadbegy, M., Bahram, M., Soleimani, M.J. 2015. Green synthesis of silver nanoparticles usinglactose sugar andevaluation of their antimicrobial activity. Der Pharma Chemica, 7(10):442-452.

Matos, R.A. and Courrol, L.M. 2014. Salvia and light as templates for the green synthesis of silver nanoparticles. Colloids and Surfaces A: Physicochemical and Engineering Aspects. 441: 539-543.

Mukherjee, P., Roy, M., Mandal, B.P., Dey, G.K., Mukherjee, P.K., Ghatak, J., Tyagi, A.K., Kale, S.P. 2008. Green synthesis of highly stabilized nanocrystalline silver particles by a non-pathogenic and agriculturally important fungus T. asperellum. Nanotechnology. 19: 1-7.

Narayanan, K.B., Sakthivel, N. 2010. Biological Synthesis of Metal Nanoparticles by 
Microbes, Adu, Colloid Interface Sci.156: 1-

13.

Noorbakhsh, F. 2011. Antifungal Effects of Silver Nanoparticle alone and with Combination of Antifungal Drug on Dermatophyte Pathogen Trichophyton Rubrum. International Conference on Bioscience, Biochemistry and Bioinformatics IPCBEE, IACSIT Press, Singapore 5: $468 \mathrm{p}$.

Önen, H., Altuntaş, E., Özgöz, E., Bayram, M., Özcan, S. 2014. Moisture effect on physical properties of Knotweed (Polygonum Cognatum Meissn), Journal of Agricultural Faculty of Gaziosmanpasa University, 31 (2): 15-24.

Pal, S., Tak, Y., Song, J. 2007. Does The Antibacterial Activity Of Silver Nanoparticles Depend On The Shape Of The Nanoparticle? A Study of the Gram-Negative Bacterium Escherichia coli. Applied and Enviromental Microbiology. 73(6): 1712-1720.

Pande, N.S., Kaurjaspal, D., Chabukswar, A., Chabukswar, V., Ambekar, J. 2015. Facile Green Route Synthesis of Silver Nanoparticles Usıng Natural Polymer and Their Antibacterial Activity. Cellulose Chem. Technol., 49 (1): 29-33.

Phanjom, P., Ahmed, G. 2017. Effect of different physicochemical conditions on the synthesis of silver nanoparticles using fungal cell filtrate of Aspergillus oryzae (MTCC No. 1846) and their antibacterial effects. Adv. Nat. Sci. Nanosci. Nanotechnol. 8: 1-13.

Saifuddin, N., Wong, C.W., Yasumira, A.A. 2008. Rapid Biosynthesis of Silver Nanoparticles Using Culture Supernatant of Bacteria with Microwave Irradiation. E-Journal of Chemistry. 6(1): 61-70.

Sarkar, J., Chattopadhyay, D., Patra, S., Singh Deo, S., Sinha, S., Gosh, M., Mukherjee, A., Acharya, K. 2011. Alternarıa Alternata Mediated Synthesıs of Proteın Capped Sılver Nanopartıcles and Their Genotoxıc Actıvity. Digest Jour. of Nanomater and Biostructures, 6 (2): 563-573.

Shahverdi, A.R., Fakhimi, A., Shahverdi, H.R., Minaian, S. 2007. Synthesis and effect of silver nanoparticles on the antibacterial activity of different antibiotics against Staphylococcus aureus and Escherichia coli. Nanomedicine. 3: 168-71. 